\title{
Effect of sodium gluconate on the solubility of calcium lactate
}

\author{
C. Phadungath* and L. E. Metzgert ${ }^{1}$ \\ *Midwest Dairy Foods Research Center, University of Minnesota, St. Paul 55108 \\ †Dairy Science Department, South Dakota State University, Brookings 57007
}

\section{ABSTRACT}

Calcium and lactate are present in excess of their solubility in Cheddar cheese. Consequently, calcium lactate crystals (CLC) are a common defect in Cheddar cheese. A novel approach for preventing CLC is the addition of sodium gluconate. Sodium gluconate has the potential to increase the solubility of calcium and lactate by forming soluble complexes with calcium and lactate ions, and preventing them from being available for the formation of CLC. The objective of this study was to determine if sodium gluconate could increase the solubility of calcium lactate $\left(\mathrm{CaL}_{2}\right)$. Seven $\mathrm{CaL}_{2}$ solutions $(5.31 \% \mathrm{wt} / \mathrm{wt})$ with 7 levels of sodium gluconate $(0,0.5,1,1.5,2,3$, and $4 \% \mathrm{wt} / \mathrm{wt})$ were made in triplicate. Solutions were stored at $7^{\circ} \mathrm{C}$ for $21 \mathrm{~d}$, and were visually inspected for CLC formation. Subsequently, they were filtered to remove CLC and the supernatant was analyzed for lactic acid and gluconic acid by HPLC and for calcium by atomic absorption spectroscopy. The visual inspection demonstrated that CLC were formed in the solution with $0 \%$ gluconate after the first day of storage and CLC continued to accumulate over time. A minute amount of CLC was also visible in the solution with $0.5 \%$ gluconate after $21 \mathrm{~d}$ of storage, whereas CLC were not visible in the other solutions. The HPLC results indicated a higher concentration of calcium and lactic acid in the filtrate from the solutions containing added gluconate. Thus, sodium gluconate can increase the solubility of $\mathrm{CaL}_{2}$.

Key words: calcium lactate crystal, sodium gluconate

\section{INTRODUCTION}

Calcium lactate crystals (CLC) can appear within and on the surface of hard-type cheese, especially Cheddar cheese after approximately 6 mo of aging. Calcium lactate crystals have been reported in Cheddar cheese as early as 1938 and are primarily composed of calcium lactate pentahydrate $\left[\mathrm{Ca}\left(\mathrm{CH}_{3} \mathrm{CHOHCOO}\right)_{2} \cdot 5 \mathrm{H}_{2} \mathrm{O}\right]$,

Received May 18, 2011.

Accepted July 5, 2011.

${ }^{1}$ Corresponding author: lloyd.metzger@sdstate.edu where 5 molecules of water are incorporated into the crystal lattice (Tuckey et al., 1938; McDowall and McDowell, 1939; Dorn and Dahlberg, 1942; Shock et al., 1948; Farrer and Hollberg, 1960; Severn et al., 1986). A potential pathway for the formation of CLC was proposed by Dybing et al. (1988). The solubility of anhydrous Ca-L-lactate is $3.38 \mathrm{~g} / 100 \mathrm{~g}$ of water at $4^{\circ} \mathrm{C}$ (Kubantseva et al., 2004), which provides $0.62 \mathrm{~g}$ of calcium and $2.76 \mathrm{~g}$ of lactate per $100 \mathrm{~g}$ of water. Thus, it is believed that CLC only form when greater than 0.62 $\mathrm{g}$ of calcium and $2.76 \mathrm{~g}$ of lactate per $100 \mathrm{~g}$ of water are present in cheese. However, the typical concentration of soluble calcium and lactate in the serum phase of aged Cheddar cheese is $1.06 \mathrm{~g} / 100 \mathrm{~g}$ and $3.73 \mathrm{~g} / 100$ $\mathrm{g}$, respectively (Morris et al., 1988). Consequently, the concentration of soluble calcium and lactate are in excess of their solubility at $4^{\circ} \mathrm{C}$ in a typical Cheddar cheese. Because calcium and lactate ions are in a supersaturate state in the cheese serum phase, crystallization at nucleation sites occurs. A continuous movement of calcium and lactate ions to the nucleation sites then causes the sites to become macrocrystals (Dybing et al., 1988; Kubantseva and Hartel, 2002; Swearingen et al., 2004).

In an aqueous solution, sugars can form complexes with metal cations by displacing water molecules in the solvation sphere of cations with their $-\mathrm{OH}$ groups. At least $3-\mathrm{OH}$ groups are required for complex formation in this system. The complex-forming ability of sugars is considerably enhanced when an anchoring group such as $-\mathrm{COOH}$ is introduced into the sugar molecules and they become sugar acids (Gyurcsik and Nagy, 2000; Nagy and Szorcsik, 2002). Because of an increasing interest in utilization of organic sequestering agents, sugar acids, which are compounds that have promising ability for this purpose, have become the subject of interest for more than $50 \mathrm{yr}$ (Mehltretter et al., 1953). Gluconic acid, which is a sugar acid, and its salts have been used as sequestering agents for metal ions in industrial, medical, and agricultural applications (Escandar and Sala, 1992). Sodium gluconate is a sodium salt of gluconic acid, and it is able to chelate and form stable complexes with metal ions, which include $\mathrm{Ca}$ (II), $\mathrm{Cu}$ (II), Fe (II), Fe (III), Co (II), Ni (II), Cd (II), Hg (II), 
$\mathrm{Pb}$ (II), Al (III), Ga (III), and In (III) (Escandar and Sala, 1992; Gyurcsik and Nagy, 2000). Gluconic acid can be produced by chemical and biological processes. The chemical processes include the chemical oxidation of glucose in alkaline media and electrolytic oxidation of an alkaline solution of glucose. The biological processes include the fermentation of glucose solution by fungi and bacteria. The chemical method is a simple one-step process, but because of the low selectivity, this method is not suitable for producing gluconic acid on an industrial scale. Thus, the fermentation process utilizing fungi Aspergillus niger is the dominant technique for producing gluconic acid in the industry (Prescott et al., 1953; Ramachandran et al., 2006). Recent developments in gluconic acid production include finding an alternative and cheaper carbohydrate source such as agro-food byproducts, which include sugarcane molasses, beet molasses, grape must, and banana must, to meet the higher demand for gluconic acid (Singh and Kumar, 2007).

Abbadi et al. (1999) studied the Ca-sequestering capability of polyhydroxycarboxylic acids (aldonic and aldaric acids). Sodium gluconate and sodium galactonate were used as representatives of aldonic acids, whereas disodium glucarate and disodium galactarate were used as representatives of aldaric acids. Their results indicated that all aldonates and aldarates were able to sequester calcium ions via their hydroxycarboxylate groups. Gluconate has also been used in other areas because of its chelating ability. For example, it has been used to prevent the milkstone formation in the milk tank (Prescott et al., 1953), inhibit corrosion of carbon steel in chloride solutions (Lahodny-Šarc et al., 2000), remove heavy metals from soil components and soils (Fischer and Bipp, 2002), decrease paint stripping time by solubilizing the surface pigment adhering to metal after stripping, and eliminating rust spots on bottle necks, thus increasing efficiency in bottle washing. Gluconic acid and gluconate have also been used in the food industry as food additives and ingredients and have generally recognized as safe status (FDA, 2010). It was recently reported that the solubility of calcium lactate $\left(\mathbf{C a L}_{2}\right)$ with a combination of gluconate was $33.4 \%$ higher than the solubility of $\mathrm{CaL}_{2}$ alone (Jungbunzlauer Ladenburg GmbH, 2002). This previous research indicates that a potential approach for preventing CLC formation in Cheddar cheese is to add sodium gluconate during the manufacturing process. Sodium gluconate addition could increase the solubility of calcium and lactate in the serum phase by forming complexes with one or both of the calcium and lactate ions, and removing one or both of the calcium and lactate ions from being available for the formation of CLC. The objective of this study was to determine if sodium gluconate could increase the solubility of calcium and lactate in model solutions.

\section{MATERIALS AND METHODS}

\section{Solubility Model}

Three replications of $7 \mathrm{CaL}_{2}$ solutions were prepared by dissolving $7.5 \%$ (wt/wt) calcium L-lactate pentahydrate powder $\left[\mathrm{Ca}\left(\mathrm{CH}_{3} \mathrm{CHOHCOO}\right)_{2} \cdot 5 \mathrm{H}_{2} \mathrm{O}\right.$, USP grade; Fisher Chemicals, Fair Lawn, NJ], $0.3 \%$ (wt/wt) potassium sorbate (99\%; Alfa Aesar, Ward Hill, MA), and 1 of 7 levels of sodium gluconate powder ( $\mathrm{NaC} 6 \mathrm{H} 11 \mathrm{O} 7$; PMP Fermentation Products Inc., Chicago, IL): 0 (control), $0.5,1,1.5,2,3$, and $4 \%$ (wt/wt) in distilled water to get a total weight of $100 \mathrm{~g}$. The $7.5 \%$ calcium lactate pentahydrate powder provided $5.31 \%$ (wt/wt) $\mathrm{CaL}_{2}$ in each solution and the potassium sorbate was used for mold inhibition. A piece of $1.5 \times 3 \mathrm{~cm}$ sand paper (Wetordry Sandpaper 9085NA, Super Fine 400 grit; 3M, St. Paul, MN) was also placed in each solution to provide a nucleation site for crystal development.

The solutions were stored for $21 \mathrm{~d}$ at $7^{\circ} \mathrm{C}$, which is a typical aging temperature for Cheddar cheese. The storage period of $21 \mathrm{~d}$ was selected because previous research has demonstrated that the true equilibrium of $\mathrm{CaL}_{2}$ solution was reached in $21 \mathrm{~d}$ (Kubantseva et al., 2004). Each solution was visually inspected for CLC formation throughout the storage time. After $21 \mathrm{~d}$, the solutions were filtered (Whatman \#4; Whatman International Ltd., Maidstone, UK) at $7^{\circ} \mathrm{C}$ to remove CLC. The supernatant was analyzed for lactic acid, gluconic acid, and calcium content. The $\mathrm{pH}$ of each solution was measured before and after storage, and the $\mathrm{pH}$ values for all solutions were similar and ranged from 6.87 to 6.91. Previous research has reported that this range in $\mathrm{pH}$ does not affect the solubility of $\mathrm{CaL}_{2}$ (Kubantseva and Hartel, 2002).

\section{Analysis of Lactic and Gluconic Acids}

Lactic and gluconic acids were determined in the filtered supernatant using an HPLC procedure adapted from Upreti et al. (2006). For the sample preparation, 2 $\mathrm{mL}$ of the $\mathrm{CaL}_{2}$ supernatant was mixed with $10 \mathrm{~mL}$ of $0.013 \mathrm{~N}$ sulfuric acid. The mixture was filtered through a $0.22-\mu \mathrm{m}$ filter unit [Millex-GV Syringe-Driven Filter Unit (nonsterile), Millipore Corp., Bedford, MA]. Approximately 0.5 to $1 \mathrm{~mL}$ of the collected filtrate was directly injected into the HPLC system using a 1-mL syringe (Tuberculin Syringes without needle, Monoject; Sherwood Medical, St. Louis, MO).

The HPLC system (AKTA design; Pharmacia Biotech AB, Uppsala, Sweden) was composed of a solvent 
delivery unit (Pump P-900) and sample injection loop, a variable wavelength UV/visible detector (UV-900), and data processing software (Unicorn version 4.0; Amersham Pharmacia Biotech AB, Uppsala, Sweden). The system was externally equipped with a refractive index detector (Beckman 156 Refractive Index detector; Beckman, Berkeley, CA), and a column heater (Hot Pocket; Thermo Hypersil-Keystone Inc., Bellefonte, PA). The column used for separation of the analytes was a cation-exchange column with the dimension 300 $\times 7.8 \mathrm{~mm}$ i.d. (Aminex $\mathrm{HPX}-87 \mathrm{H}$ ) held at $65^{\circ} \mathrm{C}$, with a cation $\mathrm{H}^{+}$microguard cartridge (Bio-Rad Laboratories Inc., Hercules, CA). Analysis was performed at $0.8 \mathrm{~mL} /$ min flow rate using $0.013 N$ sulfuric acid (Fisher Scientific Co. LLC, Fair Lawn, NJ) as the mobile phase. Lactic acid was detected using the UV detector set at $210 \mathrm{~nm}$, and the refractive index detector was used for quantification of gluconic acid.

Quantification of analytes was based on the external standard method. L-(+)-Lactic acid solution (30\% in water by weight; Sigma-Aldrich Inc., St. Louis, MO), and sodium gluconate powder (PMP Fermentation Products Inc.) were used to make stock solutions of lactic acid, and gluconic acid, respectively. The stock solutions were sufficiently diluted with $0.013 \mathrm{~N}$ sulfuric acid to obtain the desired concentration range of analytes to establish standard curves. The analytes were then quantified by the best-fit standard curves prepared by linear regression analysis of peak area versus different concentrations of the analytes.

\section{Analysis of Calcium Content}

Calcium content was determined by an atomic absorption spectroscopy procedure adapted from Metzger et al. (2000). For sample preparation, $1 \mathrm{~mL}$ of supernatant was diluted with $19 \mathrm{~mL}$ of distilled water. Then, $1 \mathrm{~mL}$ of the dilution was mixed with $29 \mathrm{~g}$ of $12 \%$ (wt/ vol) trichloroacetic acid (Fisher Scientific Co. LLC). After $30 \mathrm{~min}$, the mixture was filtered through filter paper (Whatman 541; Whatman International Ltd.). Subsequently, $10 \mathrm{~g}$ of filtrate was added to $9.6 \mathrm{~g}$ of distilled water and $0.4 \mathrm{~g}$ of $5 \%$ lanthanum oxide (Sigma Chemical Co., St. Louis, MO). The final concentration of trichloroacetic acid and lanthanum oxide in each sample was $6 \%$ (wt/vol) and $0.02 \%$ (wt/vol), respectively. Calibration standards were prepared using a calcium reference solution (SC191-500; Fisher Scientific Co. LLC). The calcium reference solution was mixed with trichloroacetic acid, lanthanum oxide, and distilled water to obtain calibration standards containing $0,4,6$, $8,10,12$, and $16 \mathrm{mg} / \mathrm{kg}$ of calcium. All standards also contained $6 \%(\mathrm{wt} / \mathrm{vol})$ trichloroacetic acid and $0.02 \%$ (wt/vol) lanthanum oxide. Each calibration standard and sample was aspirated into an atomic absorption spectrophotometer (model 2380; Perkin Elmer Corp., Norwalk, CT), which was equipped with a calcium lamp (0303-6017 Perkin Elmer Corp.) for calcium content determination. A standard curve was prepared from the calibration standards and the calcium content of the samples was quantified from linear regression analysis of absorbance versus concentration of the standards.

\section{Statistical Analyses}

A $7 \times 2$ factorial model with 3 replications was used for statistical analysis. The PROC GLM procedure of SAS, which involved 2 factors (treatment: 7 levels of sodium gluconate, and storage: before and after storage) as class variables, was used to compare lactic acid, gluconic acid, and calcium content. When significant differences occurred $(P \leq 0.05)$, the treatment means were compared by the Tukey Honestly Significant Difference test (SAS Institute, 1990).

\section{RESULTS AND DISCUSSION}

\section{Visual Inspection}

A visual inspection of the solutions demonstrated that CLC were formed in the solution with $0 \%$ gluconate after the first day of storage and CLC continued to accumulate over time. A minute amount of CLC was also visible in the solution with $0.5 \%$ gluconate after $21 \mathrm{~d}$ of storage, whereas CLC were not visible in the other solutions at any time. The 7 solutions after $21 \mathrm{~d}$ of storage are shown in Figure 1.

\section{Analyses of Lactic Acid, Gluconic Acid, and Calcium}

Table 1 shows mean squares and probabilities of percent $\mathrm{Ca}$, percent lactic acid, and percent gluconic acid. From Table 1, treatment, storage, and the interaction of term of treatment and storage had significant effects $(P<0.05)$ on percent $\mathrm{Ca}$, percent lactic acid, and percent gluconic acid, whereas replications had significant effect $(P<0.05)$ on percent Ca. Table 2 shows the mean $\mathrm{Ca}$, lactic acid, and gluconic acid contents of each treatment at $0 \mathrm{~d}$ of storage. As described previously, $\mathrm{CaL}_{2}$ solutions were prepared by dissolving $7.5 \%$ (wt/wt) calcium L-lactate pentahydrate powder $\left[\mathrm{Ca}\left(\mathrm{CH}_{3} \mathrm{CHOHCOO}\right)_{2} \cdot 5 \mathrm{H}_{2} \mathrm{O}\right]$. This concentration of calcium lactate pentahydrate powder provided $5.31 \%$ (wt/wt) $\mathrm{CaL}_{2}$ in each solution. Calcium lactate $\left[\mathrm{Ca}\left(\mathrm{CH}_{3} \mathrm{CHOHCOO}\right)_{2}\right]$ contains approximately $18.33 \%$ $\mathrm{Ca}$ and $81.67 \%$ lactate, which corresponds to $0.97 \% \mathrm{Ca}$ and $4.34 \%$ lactate. At $0 \mathrm{~d}$ of storage, the values ranged from 1.026 to $1.033 \%$ for $\mathrm{Ca}$ and from 4.39 to $4.45 \%$ 

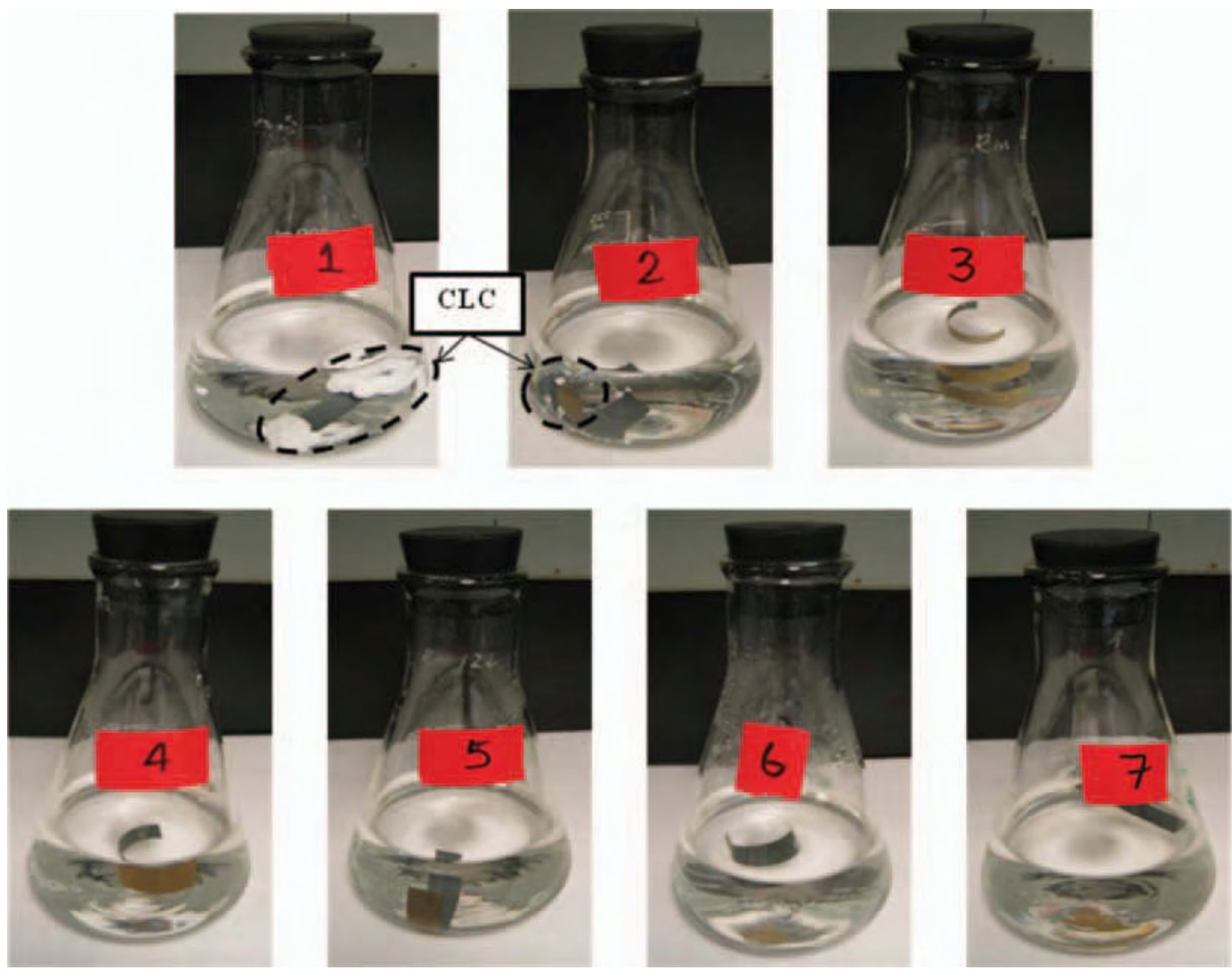

Figure 1. Calcium lactate $\left(\mathrm{CaL}_{2}\right)$ solutions after $21 \mathrm{~d}$ of storage. The solutions contained different amounts of sodium gluconate: (1) $0 \%$ (control), (2) $0.5 \%,(3) 1 \%,(4) 1.5 \%,(5) 2 \%,(6) 3 \%$, and (7) $4 \%$. CLC = calcium lactate crystals. Color version available in the online PDF.

for lactate. No differences $(P>0.05)$ were found in the $\mathrm{Ca}$ or lactate concentration among the treatments. Sodium gluconate (NaC6H11O7) contains approximately $89 \%$ gluconic acid. As expected, the concentrations of gluconic acid measured by HPLC were relatively close to $89 \%$ of the amount of sodium gluconate added to each solution (i.e., $0.5 \times 89 \%=0.45)$. As the actual concentration of Ca, lactic acid, and gluconic acid at d 0 were close to the targeted levels for each treatment, this indicated that all solutions were properly prepared.

Table 3 shows the mean Ca, lactic acid, and gluconic acid values of each treatment at $21 \mathrm{~d}$ of storage. The Ca and lactic acid contents of the control solution (treatment 1$)$ were lower $(P<0.05)$ than the other

Table 1. Mean squares and probabilities (in parentheses) for percentage Ca, percentage lactic acid, and percentage gluconic acid in calcium lactate $\left(\mathrm{CaL}_{2}\right)$ solutions at $0 \mathrm{~d}$ and after $21 \mathrm{~d}$ of storage

\begin{tabular}{lcccc}
\hline Factor & df & $\begin{array}{c}\text { Calcium } \\
(\%)\end{array}$ & $\begin{array}{c}\text { Lactic } \\
\text { acid }(\%)\end{array}$ & $\begin{array}{c}\text { Gluconic } \\
\text { acid }(\%)\end{array}$ \\
\hline Treatment $^{1}$ & 6 & $0.791 \times 10^{-2 *}$ & $0.1365^{*}$ & $10.44^{*}$ \\
& & $(<0.01)$ & $(<0.01)$ & $(<0.01)$ \\
Replications & 2 & $0.545 \times 10^{-3 *}$ & 0.0037 & $0.710 \times 10^{-3}$ \\
& & $(0.006)$ & $(0.1845)$ & $(0.6618)$ \\
Storage $^{2}$ & 1 & $0.847 \times 10^{-2 *}$ & $0.2417^{*}$ & $0.0387^{*}$ \\
& & $(<0.01)$ & $(<0.01)$ & $(<0.01)$ \\
Treatment $\times$ storage & 6 & $0.768 \times 10^{-2 *}$ & $0.1339^{*}$ & $0.439 \times 10^{-2 *}$ \\
Error & & $(<0.01)$ & $(<0.01)$ & $(0.0417)$ \\
& 26 & $0.870 \times 10^{-4}$ & $0.20 \times 10^{-2}$ & $0.169 \times 10^{-2}$ \\
\hline
\end{tabular}

${ }^{1}$ Solutions contained different amount of sodium gluconate: (1) 0\% (control), (2) 0.5\%, (3) 1\%, (4) 1.5\%, (5) $2 \%,(6) 3 \%$, and (7) $4 \%$.

${ }^{2}$ Solutions were analyzed for lactic acid, gluconic acid, and calcium before $(0 \mathrm{~d})$ and after storage $(21 \mathrm{~d})$.

*Statistically significant at $P<0.05$. 
Table 2. Mean calcium, lactic acid, and gluconic acid in calcium lactate $\left(\mathrm{CaL}_{2}\right)$ solutions at $0 \mathrm{~d}$ of storage

\begin{tabular}{lccccccc}
\hline & \multicolumn{7}{c}{ Treatment (\% sodium gluconate) } \\
\cline { 2 - 7 } Component & $1(0 \%)$ & $2(0.5 \%)$ & $3(1 \%)$ & $4(1.5 \%)$ & $5(2 \%)$ & $6(3 \%)$ & $7(4 \%)$ \\
\hline Calcium (\%) & 1.028 & 1.033 & 1.027 & 1.026 & 1.027 & 1.029 & 1.031 \\
Lactic acid (\%) & 4.42 & 4.42 & 4.43 & 4.44 & 4.39 & 4.45 & 4.39 \\
Gluconic acid (\%) & $0.00^{\mathrm{g}}$ & $0.43^{\mathrm{f}}$ & $0.91^{\mathrm{e}}$ & $1.40^{\mathrm{d}}$ & $1.81^{\mathrm{c}}$ & $2.89^{\mathrm{b}}$ & $3.76^{\mathrm{a}}$ \\
\hline a-g
\end{tabular}

${ }^{\mathrm{a}-\mathrm{g}}$ Means within the solutions across the row without common superscripts differ (Tukey Honestly Significant Difference test at $P<0.05)$.

treatments that contained sodium gluconate. When comparing the solutions before and after storage (Table 2 vs. Table 3), both Ca and lactic acid in the control solutions after $21 \mathrm{~d}$ of storage were significantly lower $(P<0.05)$ than at $\mathrm{d} 0(1.028$ vs. 0.836 and 4.42 vs. 3.59 for Ca and lactic acid, respectively). No differences $(P>0.05)$ existed in $\mathrm{Ca}$ and lactate contents in treatments $2,3,4,5,6$, and 7 at 0 and $21 \mathrm{~d}$ of storage. The decrease of $\mathrm{Ca}$ and lactic acid in the control solution after $21 \mathrm{~d}$ of storage is in accordance with results from visual inspection, where CLC were visible in the control solutions after $21 \mathrm{~d}$ of storage. The minute amount of CLC in treatment 2 did not $(P<0.05)$ influence the concentration of $\mathrm{Ca}$ and lactate in the filtrate. These results indicate that sodium gluconate addition to $\mathrm{CaL}_{2}$ solutions increase the solubility of $\mathrm{CaL}_{2}$. It is possible that the increase in the solubility of $\mathrm{CaL}_{2}$ is a result of complex formation with gluconate.

\section{Sodium Gluconate as a Ca Sequestrant}

The 3 most commonly observed modes of Ca-carboxylate interactions are (1) the unidentate mode, where the $\mathrm{Ca}$ ion interacts with only 1 of the 2 oxygen atoms of the carboxylate group; (2) the $\alpha$ mode, where the Ca ion is chelated by a carboxylic oxygen atom combined with a suitable ligand atom attached to the $\alpha$ position; and (3) the bidentate mode, where the Ca ion is chelated by the pair of carboxylic oxygen atoms. If the suitable ligand is attached to the carboxylate groups, the $\alpha$-mode chelation is found to be the most favorable Ca-chelating mode (Einspahr and Bugg, 1981). Sodium gluconate is a polyhydroxycarboxylic acid, and it has the ability to form water-soluble complexes with calcium ions, which could result in calcium-lactate-gluconate (CLG) complexes. Its chelating ability is suggested to be from the $\alpha$-mode chelation with 1 of the carboxylic oxygen atoms and the $\alpha$-hydroxylic ligand. This $\alpha$-mode chelation allows both functional groups to be in a position to bind a $\mathrm{Ca}$ ion in the formation of a stable 5-membered chelate ring (Wieczorek et al., 1996; Saladini et al., 2001; Ramachandran et al., 2006).

\section{Possible Formation of CLG Complexes}

Our proposed mechanism for the formation of CLG complexes in the model solution is shown in Figure 2. In this mechanism, $\mathrm{Ca}$ ions are able to interact with oxygen from water molecules, oxygen from carboxyl groups of both gluconate and lactate, and oxygen from hydroxyl groups of gluconate. It was suggested by Cook and Bugg (1977) that the Ca-oxygen bond strength from Ca-water (ion-dipole bond) is weaker than that from Ca-carboxyl and Ca-hydroxyl (electrostatic bond). Thus, it is possible that once lactic acid and gluconic acid dissociate, their ions are competing to replace weaker $\mathrm{Ca}$-water bonds from hydrated $\mathrm{Ca}$ ions, resulting in CLG complexes. In order for crystals to form, a substance has to be in a position that will allow it to stack and layer in the most compact way possible (Jacques et al., 1981). It is possible that the bulky side chain of gluconic acid may provide steric hindrance that prevents CLC formation.

\section{CONCLUSIONS}

It is apparent that sodium gluconate can significantly increase the solubility of $\mathrm{CaL}_{2}$. However, the solution in

Table 3. Mean calcium, lactic acid, and gluconic acid in calcium lactate $\left(\mathrm{CaL}_{2}\right)$ solutions after $21 \mathrm{~d}$ of storage

\begin{tabular}{lccccccc}
\hline & \multicolumn{7}{c}{ Treatment (\% sodium gluconate) } \\
\cline { 2 - 7 } Component & $1(0 \%)$ & $2(0.5 \%)$ & $3(1 \%)$ & $4(1.5 \%)$ & $5(2 \%)$ & $6(3 \%)$ & $7(4 \%)$ \\
\hline Calcium (\%) & $0.836^{\mathrm{b}}$ & $1.028^{\mathrm{a}}$ & $1.031^{\mathrm{a}}$ & $1.026^{\mathrm{a}}$ & $1.026^{\mathrm{a}}$ & $1.024^{\mathrm{a}}$ & $1.026^{\mathrm{a}}$ \\
Lactic acid (\%) & $3.59^{\mathrm{b}}$ & $4.42^{\mathrm{a}}$ & $4.41^{\mathrm{a}}$ & $4.40^{\mathrm{a}}$ & $4.36^{\mathrm{a}}$ & $4.35^{\mathrm{a}}$ & $4.34^{\mathrm{a}}$ \\
Gluconic acid (\%) & $0.00^{\mathrm{g}}$ & $0.42^{\mathrm{f}}$ & $0.86^{\mathrm{e}}$ & $1.31^{\mathrm{d}}$ & $1.79^{\mathrm{c}}$ & $2.79^{\mathrm{b}}$ & $3.62^{\mathrm{a}}$ \\
\hline
\end{tabular}

${ }^{\mathrm{a}-\mathrm{g}}$ Means within the solutions across the row without common superscripts differ (Tukey Honestly Significant Difference test at $P<0.05)$. 


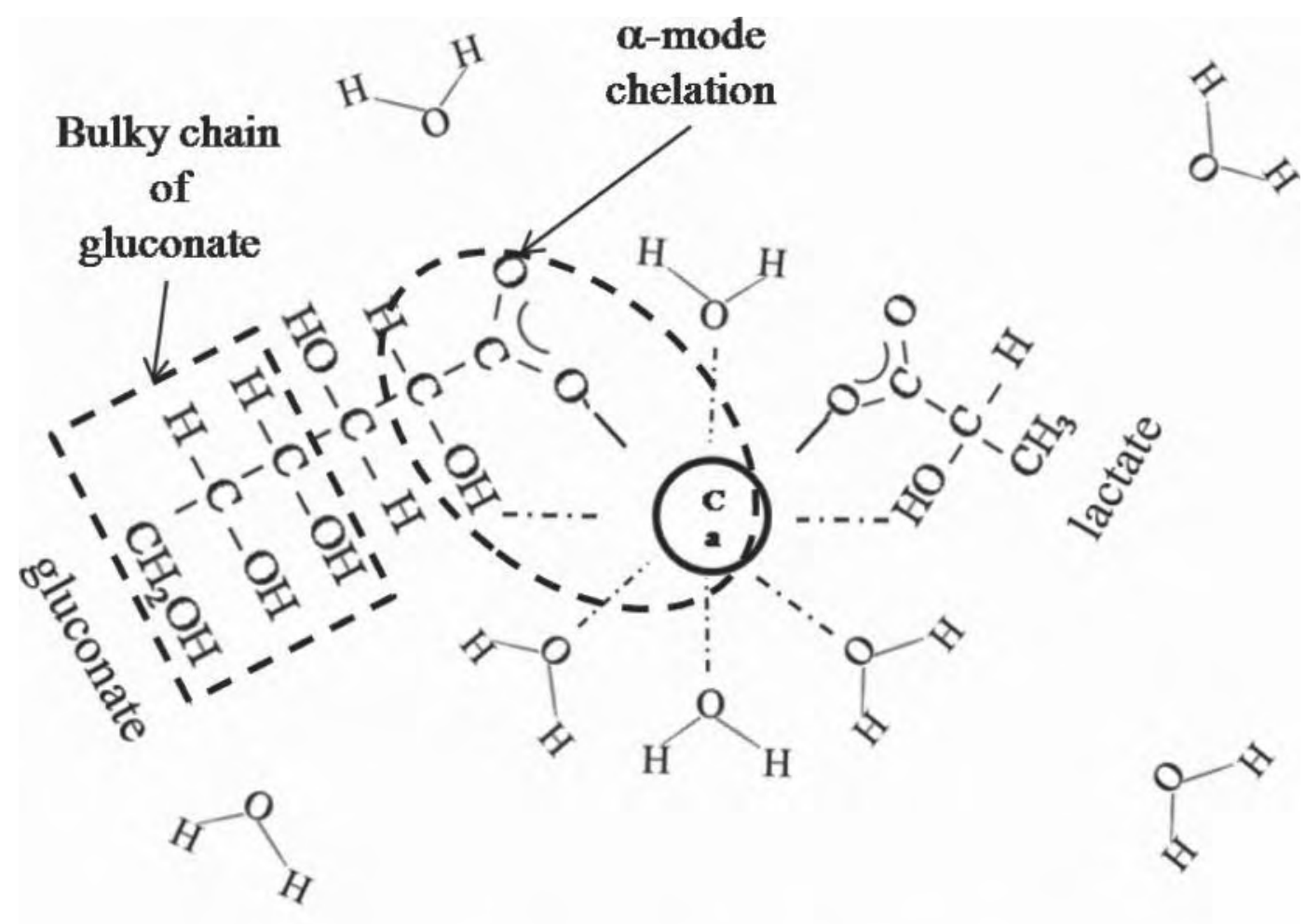

\section{Ca-lactate-gluconate}

Figure 2. Proposed mechanism of Ca-lactate-gluconate formation with lactate and gluconate ions competing for weaker Ca-hydration bonds resulting in Ca-lactate-gluconate complexes.

this study was a simple model containing only calcium and lactate ions, whereas real Cheddar cheese serum is a complex system containing several other constituents such as sodium, chloride, phosphorus, potassium, magnesium, citrate, acetate, and sulfate ions.

\section{ACKNOWLEDGMENTS}

The financial support of the Midwest Dairy Foods Research Center (St. Paul, MN) is gratefully acknowledged.

\section{REFERENCES}

Abbadi, A., K. F. Gotlieb, J. B. M. Meiberg, J. A. Peters, and H. van Bekkum. 1999. New Ca-sequestering materials based on the oxidation of the hydrolysis products of lactose. Green Chem. $1: 231-235$.

Cook, W. J., and C. E. Bugg. 1977. Structure of calcium-carbohydrate complexes. Pages 231-256 in Metal-ligand Interactions in Organic Chemistry and Biochemistry, Part 2. B. Pullman and N. Goldblum, ed. D. Reidel Publishing Co., Dordrecht, the Netherlands.

Dorn, F. L., and A. C. Dahlberg. 1942. Identification of the white particles found on ripened Cheddar cheeses. J. Dairy Sci. 25:31-36.
Dybing, S. T., J. A. Wiegand, S. A. Brudvig, E. A. Huang, and R C. Chandan. 1988. Effect of processing variables on the formation of calcium lactate crystals on Cheddar cheese. J. Dairy Sci. 71:1701-1710

Einspahr, H., and C. E. Bugg. 1981. The geometry of calcium-carbohydrate interactions in crystalline complexes. Acta Crystallogr. B 37:1044-1052.

Escandar, G. M., and L. F. Sala. 1992. Complexes of Cu(II) with Daldonic and D-alduronic acids in aqueous solution. Can. J. Chem. 70:2053-2057.

Farrer, K. T. H., and W. C. J. Hollberg. 1960. Calcium lactate on rindless cheese. Aust. J. Dairy Technol. 15:151-152.

FDA. 2010. 21 CFR, Part 182.6757. United States FDA, Department of Health and Human Services, Washington, DC.

Fischer, K., and H.-P. Bipp. 2002. Removal of heavy metals from soil components and soils by natural chelating agents. Part II. Soil extraction by sugar acids. Water Air Soil Pollut. 138:271-288.

Gyurcsik, B., and L. Nagy. 2000. Carbohydrates as ligands: Coordination equilibria and structure of the metal complexes. Coord. Chem. Rev. 203:81-149.

Jacques, J., A. Collet, and S. H. Willen. 1981. Enantiomers, Racemates, and Resolutions. John Wiley and Sons, New York, NY.

Jungbunzlauer Ladenburg GmbH. 2002. Calcium lactate gluconateThe innovative solution for extra calcium. Innovations in Food Technology 16:1-3. Accessed Aug. 15, 2011. http://www.jungbunzlauer.com/media/uploads/pdf/Special_Salts/Calcium_Lactate_ Gluconate_Aug02.pdf.

Kubantseva, N., and R. W. Hartel. 2002. Solubility of calcium lactate in aqueous solution. Food Rev. Int. 18:135-149. 
Kubantseva, N., R. W. Hartel, and P. A. Swearingen. 2004. Factors affecting solubility of calcium lactate in aqueous solutions. J. Dairy Sci. 87:863-867.

Lahodny-Šarc, O., F. Kapor, and R. Halle. 2000. Corrosion inhibition of carbon steel in chloride solutions by blends of calcium gluconate and sodium benzoate. Materials and Corrosion. 51:147-151.

McDowall, F. H., and A. K. R. McDowell. 1939. The white particles in mature Cheddar cheese. J. Dairy Res. 10:118-119.

Mehltretter, C. L., B. H. Alexander, and C. E. Rist. 1953. Sequestration by sugar acids. Ind. Eng. Chem. 45:2782-2784.

Metzger, L. E., D. M. Barbano, M. A. Rudan, and P. S. Kindstedt. 2000. Effect of milk preacidification on low fat Mozzarella cheese. I. Composition and yield. J. Dairy Sci. 83:648-658.

Morris, H. A., C. Holt, B. E. Brooker, J. M. Banks, and W. Manson. 1988. Inorganic constituents of cheese: Analysis of juice from a one-month-old Cheddar cheese and the use of light and electron microscopy to characterize the crystalline phases. J. Dairy Res. $55: 255-268$.

Nagy, L., and A. Szorcsik. 2002. Equilibrium and structural studies on metal complexes of carbohydrates and their derivatives. J. Inorg. Biochem. 89:1-12.

Prescott, F. J., J. K. Shaw, J. P. Bilello, and G. O. Cragwall. 1953 Gluconic acid and its derivatives. Ind. Eng. Chem. 45:338-342.

Ramachandran, S., P. Fontanille, A. Pandey, and C. Larroche. 2006. Gluconic acid: Properties, applications and microbial production. Food Technol. Biotechnol. 44:185-195.

Saladini, M., L. Menabue, and E. Ferrari. 2001. Sugar complexes with metal $^{2+}$ ions: Thermodynamic parameters of associations of $\mathrm{Ca}^{2+}$, $\mathrm{Mg}^{2+}$ and $\mathrm{Zn}^{2+}$ with galactaric acid. Carbohydr. Res. 336:55-61.
SAS Institute. 1990. SAS User's Guide: Statistics, Version 6.0 ed. SAS Inst. Inc., Cary, NC.

Severn, D. J., M. E. Johnson, and N. F. Olson. 1986. Determination of lactic acid in Cheddar cheese and calcium lactate crystals. J. Dairy Sci. 69:2027-2030.

Shock, A. A., W. J. Harper, A. M. Swanson, and H. H. Sommer. 1948. What's in those "white specks" on Cheddar? Wisc. Agric. Exp. Sta. Bull. 474. Univ. Wisconsin, Madison.

Singh, O. V., and R. Kumar. 2007. Biotechnological production of gluconic acid: Future implications. Appl. Microbiol. Biotechnol. 75:713-722.

Swearingen, P. A., D. E. Adams, and T. L. Lensmire. 2004. Factors affecting calcium lactate and liquid expulsion defects in Cheddar cheese. J. Dairy Sci. 87:574-582.

Tuckey, S. L., H. A. Ruehe, and G. L. Clark. 1938. X-ray diffraction analysis of white specks in Cheddar cheese. J. Dairy Sci. 21:A161. (Abstr.)

Upreti, P., L. L. McKay, and L. E. Metzger. 2006. Influence of calcium and phosphorus, lactose, and salt-to-moisture ratio on Cheddar cheese quality: Changes in residual sugars and water-soluble organic acids during ripening. J. Dairy Sci. 89:429-443.

Wieczorek, M. W., J. Blaszczyk, and B. W. Król. 1996. Effects of cation interactions on sugar anion conformation in complexes of lactobionate and gluconate with calcium, sodium, or potassium. Acta Crystallogr. C 52:1193-1198. 